\title{
If caring for a spouse with disabilities involved self reported strain, caregiver mortality was increased
}

Schulz R, Beach SR. Caregiving as a risk factor for mortality: the Caregiver Health Effects Study. JAMA 1999 Dec 15;282:2215-9.

QUESTION: Do older adults who care for a spouse with disabilities have an increased risk of mortality?

\section{Design}

A cohort study with mean follow up of 4.5 years (Caregiver Health Effects Study, a part of the Cardiovascular Health Study).

Setting

4 communities in the US.

\section{Participants}

392 caregivers whose spouses had difficulties with $\geqslant 1$ activity of daily living (ADL) or instrumental activity of daily living (IADL) because of physical or health problems or problems with confusion and 427 noncaregivers whose spouses did not have these difficulties. Mean age was 80 years (range 66-96 y), 51\% were women, and $90 \%$ were white. Inclusion criteria were age $\geqslant 65 \mathrm{y}$ and plans to live in the study area for 3 years. Exclusion criteria were being wheelchair bound at home, inability to attend evaluations, or having cancer treatment. Follow up for mortality was $100 \%$.

\section{Assessment of risk factors}

Baseline data were collected on sociodemographic factors (age, sex, race, education, and stressful life events), physical health status (prevalent disease, subclinical disease, or no disease), and caregiving status (spouse not disabled [referrant group] or caregiving defined as living with but not helping disabled spouse, helping disabled spouse with no self reported physical or emotional strain, or helping disabled spouse with strain reported).

\section{Main outcome measure}

All cause mortality.

\section{Main results}

During follow up, 103 participants died (16\% in the groups with a disabled spouse and 9\% in the group whose spouses were not disabled). After adjustment for sociodemographic factors and physical health status, caregiving with strain was associated with all cause mortality, whereas caregiving without strain or living with a disabled spouse and not helping were not associated with mortality; age, sex, race, and prevalent disease were associated with increased risk of all cause mortality (table).

\section{Conclusion}

Older adults who provided care for a disabled spouse had an increased risk of all cause mortality if the caregiving was associated with self reported physical or emotional strain.
Baseline caregiving status, sociodemographic factors, and physical health status associated with alt cause mortality in older adults who were living with a disabled spouse

\begin{tabular}{ll} 
Baseline variable & $\begin{array}{l}\text { Adjusted relative } \\
\text { risk (95\% CI) }\end{array}$ \\
\hline Helping spouse with caregiving strain & $1.63(1.00$ to 2.65$)$ \\
\hline Helping spouse but no reported strain & $1.08(0.61 \text { to } 1.90)^{\star}$ \\
\hline Not helping disabled spouse & $1.37(0.73 \text { to } 2.58)^{*}$ \\
\hline Age per year & $1.10(1.06$ to 1.14$)$ \\
\hline Sex of caregiver (men $v$ women) & $1.88(1.23$ to 2.88$)$ \\
\hline Race of caregiver (black $v$ white) & $2.00(1.03$ to 3.89$)$ \\
\hline Prevalent disease at baseline & $3.30(1.79$ to 6.08$)$ \\
\hline
\end{tabular}

*not significant

\section{COMMENTARY}

To date, researchers have not reached consensus on the effect of caregiving on the caregiver's long term health status. Studies have been small and not prospective. Schulz and Beach are the first researchers to show that caregivers who report strain are at greater risk of death. Their data indicate that, after adjusting for sociodemographic factors and physical health status, caregivers who provided support to their spouse and reported caregiving strain were 63\% more likely to die within 4 years than non-caregivers. In addition, caregivers who were older, men, black, or had $\geqslant 1$ prevalent disease had higher 4 year mortality rates. This prospective study is an important contribution to the health status and caregiving research.

Schulz and Beach used a broad definition of caregiver which specified that the spouses had difficulty with $\geqslant 1$ task of IADL or ADL. Therefore, the results of the study probably underestimate the risk of mortality for individuals caring for spouses with chronic deteriorating illnesses, such as dementia. Limitations of the study include no mention of the sex bias in assessment of tasks of IADL, and limiting the definition of caregiver strain to a simple question asking about extent of emotional or physical strain for each task helped with (any $v$ none).

With the increasing ageing population, the need for and value of caregivers will also increase. Arno $e^{t} a l^{1}$ point out the tangible value of informal caregiving to the healthcare system in terms of cost and hours of labour involved. The results of this study are relevant to all nurses who work with elderly people in primary and home care settings because they are in a position to identify spousal caregivers at serious risk of mortality. Unfortunately, little empirical evidence exists about effective interventions to reduce this strain. Until such evidence is found, nurses should identify spousal caregivers with biopsychosocial risk factors and institute individualised care strategies to assist the caregiver in reducing strain and optimising care.

Barbara Given, RN, PhD Professor, College of Nursing Michigan State University East Lansing, Michigan, USA abstract appears in Evidence Based Mental Health and ACP Journal Club. 